\title{
An Examination to Measure the Satisfaction Level of Faculty towards Work Life Balance Practices of Private and Public Universities of Delhi/NCR Region
}

\author{
Pooja Choudhary, Preeti Yadav
}

\begin{abstract}
Study aims to measure the satisfaction level of the Female Faculty towards the work life balance practices prevailing in their universities. Researcher has used both the primary and secondary data. Secondary data related to the work life balance studies, higher education system of India, universities and its types, and knowledge about the research methodology, has been used in the study. Primary data is collected in the form of perception of female faculty members towards the work life balance in public and private universities of Delhi/NCR. Total sample size was 602 female faculty members. It was found that in public universities, majority of the female faculty were found to be satisfied towards all the work life balance practices except; Facility of yoga and other clubs to cope up stress and career break for the specific purpose such as for higher education. In private universities, majority of the female faculty were found to be dissatisfied towards all the work life balance practices. Hence, female faculty working in public universities were found to be more satisfied than female faculty working in private universities.
\end{abstract}

Keywords: Work life balance, work life balance practices, faculty members, female, India, higher education system, women, universities, workplace, and stress.

\section{INTRODUCTION}

Women are the base of every institution be it their personal as well as professional spheres. They have ability to work with zeal, enthusiasm, compete devotion and ethical values. They always give priority to their family and in order to make the valuable as well as fruitful living, they have to work. They have to pass through many hardships so that they could strike a balance in their different spheres. The practices related to work life balance are primarily associated with achieving the balance between the employees' work and family life (Purohit, 2013). The working institutions are working out well with the evolving aspects with the introduction as well as acceptance of a wide variety of significant work-life balance strategies to facilitate their employees in a well manner. A healthy work-life balance cult programs encompasses the amicable strategies, support from the

Revised Manuscript Received on November 11, 2019.

* Correspondence Author

Pooja Choudhary, Research Scholar, Amity Business School, Amity University Rajasthan, Jaipur

Dr. Preeti Yadav, Associate Professor, Amity Business School, Amity University Rajasthan, Jaipur immediate boss and employers, well ness programs, fitness initiatives, consultations as well as career counseling.

The practices differ from place to place but the entire focus is not attaining the long term benefits for the employees as well as the organizations. It is the responsibility of the management to keep a proper track of the changing needs of their women employees and frame adequate separate strategies to make their living lesser complex as well as enable them to greet their changing exigencies of their personal and professional (Tabassum et al., 2011). There are many distinctive practices which are performed at different areas in India with their prime focus on the improving the ability of women teaching faculties to maintain a balance in their personal as well as professional lives. Many organizations have set up separate Human Resource department, which promote effective woke life balance policies by engrossing corporate social responsibility, employees' betterment and work life balance. They worth the women employees and focus on making provision of all those facilities, which could enable them sort out various problems encountered by them at regular intervals of time. In the words of Estes and Michael, the work life balance constitutes a work life balance practice, which includes flexible work options, support from organizations for the dependent care and family as well as personal leave (Estes and Michael, 2005). These practices are mere initiatives to retain them with the institutions and enable them to enjoy a sound personal as well as professional support. These practices engross flexibility in work practices, compressed work week by enabling the employee work a full weeks work for four days and take the fifth off, teleworking, job sharing between two employees, family leave programs, compassionate leave onsite child care and financial support, as well as elder care service (Susi and Jawaharani, 2011). The initiatives allow the employees to attain a balance between the work and personal life commitments that is right fit them. The work place is called the second home of the employees as they have to spend the portion of their valuable time at the workplace after their home. So, an amicable ambience, adequate facilities, proper benefits and support is required by the employers in order to boost the employees. All the employees are aware of the existence of prominent work life balance practices initiated and executed by their institutions. Skinner and Chapman conducted a study to analyze the impact of numerous work life balance practices of the women employees working 
across multiple domains in Australia. The study highlighted the positive impact of many employee friendly and employee centered policies like flexi schedule and flexi weeks, work from home, child care facilities, unpaid leaves and maternity leave on the productivity and balance in the personal as well as professional life of the employees (Skinner and Chapman, 2014).

Maya and Bagali highlighted the impact of emerging human resource management practices on the work life balance among the working mothers in public as well as private sector at Karnataka in India. The women employees were found highly gratifies with the immediate supervisor, working conditions as well as flexible hours of work (Maya and Bagali, 2014). Amstad et al., many employers plan and execute the fruitful strategies for reducing the gauntlets encountered by the women employees by introducing the flexible work life balance initiatives as well as supportive measures for nurturing the elders and children in the families (Amstad et al., 2011). Mauno et al., highlighted that proper support from the managers, paid parental leave, flexible working hours as well as working conditions as prominent factors to benefit the married as well as mother female employees (Mauno et al., 2010). Renda et al, in their research work conducted with the mothers having infants working with organizations in Australia reflected their preferences for the leave options, flexi work schedules, breast feeding facilities, access to the part time facilities as well as quality child care as the fruitful strategies because such pliable work patterns enable them spare the valuable time for their kids and family members (Renda et al., 2009). A study conducted among the employees working in the software industries highly recommended the trend of work from home is increasing as it saves time and energy of the women employees and they could easily dedicate it to nurture their family members (Aveline et al., 2017). They prefer the working pliable working conditions for the revival of the family life.

O'Driscoll et al. conducted a study on the female managers working in some organizations in New Zealand and depicted the positive impact of various practices like supervisor and organizational support, availability and access to the family responsive policies, sabbaticals, maternity, elder care and part time work facilities on the work life balance as well as job satisfaction among the employees (O'Driscoll et al., 2003). Moreover, another study undertaken stated the employee friendly, feasible, amicable and attractive work ambience is the key to sort out various health related problems like anxiety, stress, burnout, clashes, obesity, hypertension and other health problems among the employees. Some organizations working dealing in the service sector focus on interdependence among the employees as the important strategy to enable the employees strike an equilibrium in the several domains of their lives (Lazar et al., 2010).

Apart from this, self-rostering is another practice, which is prominently used across corporate sector, which enables the employees to encounter many gauntlets by rescheduling their work patterns and combat the irregular work schedules. The employees become able to maintain good work spirit and capable of sharing time with their families. They become able to make improvisation in their ways of operating in the organizations and it also reduces the tendency of role conflict as well as lessen the work pressure on them (Kupper, 2010). Njenga highlighted that the organizations aim at creating awareness among their women employees at regular intervals of time regarding their rights, ability to make possible changes in their work behavior so that they could be able to combat the challenges as well as make their way to the higher level of productivity, improved performance and positive work culture. The presence of such initiatives aim at enhancing the job satisfaction and work out various ways to provide the family-amicable advantages, work life initiatives for motivating the faculties to work in the organizations in a well manner.

\section{REVIEW OF LITERATURE}

Sugana and Franco (2017) analyzed the work life balance dilemmas of the nursing staff working at the private hospitals in Palayamkottai. The study highlighted the nature of the job, long working hours, and changes in the roaster as well as work pressure as a stumbling blocks in the life of nursing staff that create an imbalance in their work as well as family. Long working hours and work fatigue were found as major reasons of upheaval in their work commitments done with the hospital authorities. The staff nurses were found incapable of spending a valuable time with their children and family members. The current situations reduced their quality of life and increased the level of dissatisfaction among them. Hence, it was suggested that hospital management must focus on formulating some suitable and friendly strategies to improve the efficacy of staff members to maintain an adequate balance in work and life.

Alison and Rosalie (2015) ascertained the impact of work life balance on the employees and their lives across several domains. Work life balance is examined in context to the multiple groups like men, single parents and working women in the modern era. The researchers also explained the positive impact of work life balance strategies initiated by the organizations in terms of flexible working hours and telecommuting in rendering equivalent work as well as non-work roles. They were found satisfied in general in terms of greater life satisfaction and job gratification as well as improved behavioral approach in terms of lower employee absenteeism and job turnover. Female employees were found happier and more relaxed with the flexible environment due to their ability to spare time for their families and kids. Hence, it was supported that both employers as well as employees should consider and execute the imperative initiatives to attain a healthy work environment.

Saleh (2015) examined the impact of emotional intelligence practice across the corporate sector on the work life balance of the employees. The study revealed emotional stability as the major consequences of the emotional intelligence practice. The emotional intelligence of working employees resulted in increase in performance level and large scale monetary benefits to the organization. The entire process of decision making in the business entities was observed to be dependent upon emotional stability of the employees in the corporate entity. The research highlighted prospects for professional growth, organizational growth, 
working conditions of the organizations, duration of the job, adherence towards rights of employees as well as transfer policies as the prominent factors that affect the level of emotional intelligence among the employees. Management must make emotional quotient as the prominent criterion for recruiting the employees for the higher posts.

Mari and Mohideen (2015) conducted a study to analyze the nature of work-life balance experience by the faculties in the higher education institutions. The advancements in the technologies and changing work patterns demand for more engagement of employees in the work almost making it $24 * 7$ work environment. The sample size of the study was 100 respondents who were faculties at Government aided college from Pudukkottai and Hanjavur districts in India. The study revealed the stress faced by the employees due to dependents, role clashes, family culture, long working hours, rigidity in the practices followed in their respective institutions and lack of support from the employers. Stress was found as the root cause of major problems in the life of faculties in terms of psychological, social and family disorganization. The study evidently supported the presence of institutional support, flexibility in time, and effective working hours to enable the teaching faculties to manage their lives.

Skinner and Chapman (2014) examined the impact of family friendly policies on the work life balance of the employees working across health, public sector and social services in Australia. The diversified work culture has led to the introduction of many challenges that influence the balance in the work life and family life of the employees. Many organizations have introduced the family friendly policies to retain the employees and enhance their productivity. The study highlighted the positive impact of various work related policies like employee-centered flexible work practices, part time work, flextime, paid and unpaid leaves and access to child care facilities on the work and family life of the employees. Thus, provision of adequate work life balance policies would prove to be effective for the employees across multiple domains if these are revised at regular intervals of time as well as integrated with the mainstream policies.

Stella et al. (2014) ascertained the various practices pertaining to work life balance across educational, baking and power in Nigeria the contemporary era. The research highlighted that power sector was highly dominated by the male employees. The women employees were highly benefitted by the childcare and maternity leave. The education and banking sector had equal distribution of the male and female employees. The study also found the policies related to the educational sector to be very flexible in comparison to the other domains. Therefore, the study suggested that the management must revise and reformulate the educational strategies so that it could enhance the capabilities of the employees. There must be precise atmosphere in the organization so both male as well as female employees could function in close consortium with each other in a well manner.

Maiya and Bagali (2014) investigated the impact of various emerging HRM practices on the work life balance among working mothers. The study was conducted with 110 working mothers in private and public sector at Bangalore, Karnataka, India. The study revealed a higher degree of correlation between the difficulties faced and the balancing act to be performed by the employees. The employees were found satisfied with the working conditions, hours and immediate supervisors. The organizational support factors were also found influential for balancing the employees in their family as well as work life. The public sector lagged behind the private sector in providing training programs. Both the sectors were highly influenced by the career advancing and organizational support factors whereas moderately influenced by the balancing, psychological, advancement and personal factors. Hence, the organizations should implement balance policies and encourage the employees to make use of available practices.

Paryani (2014) highlighted the various aspects related to work-life balance in the lives of the employees. The study was conducted with 200 respondents who were the Lecturer, Associate professors, Head of the departments and Associate professors working in educational institutions of Mumbai and Pune region. The study revealed the positive correlation between Work-life balance and work policies including major factors such as flexible working hours, paid time off and Sabbaticals. The study did not find any association between provision of facilities like recreation, support programs, health programs, telephone services and work facilities and the work life balance. Moreover, employer's contribution and work-life balance was found significantly correlated with each other. Hence, the institution must create and sustain counseling amenities by appointing full time counselors. Management must provide supportive environment to the working employees to enable them get well balanced life.

Shiels (2014) highlighted the implications of changes in work life balance for job and family satisfaction. Work life balance has attracted the interests of applied business professionals as well as researchers over the last two decades. The study was conducted with 665 teachers to examine the impact of some factors on the work life balance of faculties working in Australia in the contemporary times. The research documented the various challenges faced by employees in terms of negligence of the family members, job stress, physical and mental illness, inability to cope with the transforming patterns of lives, lack of support from family members as well as disorganization in the long run. The study revealed the possibility of work-family conflict and family-work conflict in the lives of teachers. It was stressed that researchers must formulate some policies, which could prove to be beneficial for the individual workers and their families with improved gratification with their work and family life.

Pookaiyaudom (2014) investigated the perceptions of students with respect to the work life by encompassing their syllabi and curriculum. The study was undertaken with 65 students from Chaulalongkorn University with the help of questionnaire. The study revealed the good echelon of understanding and skills among the students. The study observed the higher level of work engagement and overburden of projects among the students. The students made their preferences for the indulgence in leisure and recreational activities to overcome the work burden and enhance the quality of life among the students. Therefore, the study suggested that the 
apex level must engross the recreation activities to enable the students understand the significance of work life. The students should be assigned the tasks according to their interests to enhance the quality of their work life as well. The feasible environment would lessen the student turnover as well as enhance the level of self-confidence among the students.

Delina and Raya (2013) foregrounded the various challenges encountered by the working women in striking a balance in their work and personal life. The sample size of the study was 180 respondents who were the married working females from Pondicherry. The study highlighted the inability of respondents to fulfill their personal, work, family and societal standards due to job work load, work related stress and constant anxiety. The women respondents found it difficult and complex to attain the deadlines of the various assigned tasks and long working hours, which resulted in their physical as well as psychological annihilation. The challenges encountered by the women had negative, direct and indirect impact on their quality of work and life. Hence, it was suggested that working women should spare some time for themselves to rejuvenate their mind and body. The work environment must provide them with suitable mechanisms to improve their work efficacy and quality of living with their peers as well as family.

Kumar et al., (2012) analyzed the impact of some attributes like age, point of anxiety and sex on the personal and professional life. The study was undertaken with 197 respondents who were 101 male and 96 females professional instructors in an engineering college situated at Namakall region. The study revealed marital status, working status of the partners and work pressures as the major factors that impact the family and work life of the faculties. The respondents were found incapable in balancing the two phases of their lives. The pressure of result-oriented targets was another root cause of stress among the faculty members. The young faculties were observed as quick and swift enough to attain their work life objectives as compare to the others. Hence, the study emphasized on providing the staff members with a stress free environment where they could work freely in order to achieve their personal as well as professional goals for a long span of time.

Madipelli et al. (2013) examined the various challenges encountered by the working women and the factors creating such imbalance in their lives. Women are working hand in hand with their counterparts to get livelihood for their family. The study was conducted with the experiences and the perceptions of the teachers. Most of the women respondents were found struggling with the stress due to lot of work demands, stiff working conditions, long duration of working hours, and lack of support from the family as well as husband. The multiple roles played by women in the contemporary era were the root cause of stress and work life imbalance as well as some health related problems, which lead to disorganization in the long run. Therefore, the researchers emphasized that women employees should give autonomy and flexible working hours so that they could spare some precious moments for their family members as well as lead a health life for long.

M. (2012) conducted a study to examine the impact of various factors such as personal needs, time management, team work, compensation, social needs and work aspects on the work life balance. Many working people are unable to strike a balance between their work and life due to the cutbacks where they work, changing ideologies, environmental causes and stiff competition. The sample size of the study was 100 employees working at SBM. The study revealed no significant association between the team management and compensation as well as benefits. The positive degree of correlation was found between social needs, personal needs, compensation and benefits and work. It was suggested that there is a dire need to identify the major aspects related to work-life and incorporate them appropriately so as to manage the family, interest as well as work life in a well manner. Team work could be enhanced by devising some factors like team building, team projects and making the employees aware of balance life.

Lyle (2012) examined the work life balance of employees with in the U.S. communications Industry. The organizations are highly influential in ascertaining the demands of employment and demands of the rest of their domains outside the work place. The employees were motivated by the human interaction, flexibility, compensation and benefits, well defined job expectancy and career growth, which resulted in the higher level of productivity and stronger feeling of job satisfaction among the employees. Moreover, the interpersonal relationships formed at the work place were found to have a positive impact on the lives of the employees. Leaders must encourage their employees to prioritize their personal as well as professional obligations. Leaders must enhance the collaborative association among the employees by injecting a community of honest dialogue and paying heed to the needs of the individual inside as well as outside the work place to constitute a positive work culture.

International Labour Office (2011) reviewed the work life conflicts and their impacts on the gender equality at home and work, on poverty reduction, business performance as well as social protection. The issues related to work-life balance have gained visibility on the international turf and in domestic policy agendas. Unequal share of caregiving work between women and men; changing work patterns, transforming social, demographic and environmental trends; improper family supportive public policies; impact of economic upheavals and impacts of work family tensions are the major challenges faced by the working class. Women were found incapable to have adequate access to the decent paid work. The report suggested for drawing upon effective initiatives from around to world to mitigate the conflicts so as to provide maximum benefits to the business, societies and families at large. It must be ensured that the needs of the workers must be addressed while formulating the strategies. Objectives: To measure the satisfaction level of the Female Faculty towards the work life balance practices prevailing in their universities.

\section{RESEARCH METHODOLOGY}

In current study researcher has used both the primary and secondary data. Secondary data related to the work life balance studies, higher education system of India, universities and its types, and knowledge about the research 
methodology, has been used in the study. For secondary data researcher has used books, research reports, research databases, websites, newspapers and government reports. While the major objectives of the study have been achieved using primary data only. Primary data is collected in the form of perception of female faculty members towards the work life balance in public and private universities of Delhi/NCR. 600 questionnaires were distributed to the female faculty of the public universities and 300 questionnaires were distributed to the female faculty of private universities. Out of which only 443 female faculty from public universities, and 159 female faculty from private universities; completely filled up the form, which have been used for final data analysis. The response rate was 73 percent for the public universities and 53 percent for the private universities. Total number of respondents of the study were counted as 602 female faculties. Hence, total sample size will be 602 female faculty members. Researcher has framed an instrument to measure the work life balance among female faculty based on review of literature that was used to collect primary data. Method of data collection was personal and face to face interaction with faculty members. In current study researcher has used random sampling method, as the female faculty from all the 12 universities have been selected randomly from each of the university. Researcher has visited all the departments of the 12 selected universities and approached female faculty to collect the data.

$H_{0:}$ There is no significant difference in the satisfaction level of Female Faculty towards the work life balance practices of the Public and Private universities of Delhi/NCR.

$H_{1}$ : There is significant difference in the satisfaction level of Female Faculty towards the work life balance practices of the Public and Private universities of Delhi/NCR.

\section{FINDINGS AND DISCUSSIONS}

Researcher has developed the questionnaire to collect the data related to the perception of the female faculty towards the work life balance practices prevailing in their universities, hence it is required to measure the reliability of the questionnaire. Results of the reliability has been given in this section.

Table 1: Reliability Results

\begin{tabular}{|c|c|c|c|c|}
\hline Description & $\begin{array}{c}\text { Number } \\
\text { of } \\
\text { Statemen } \\
\text { ts }\end{array}$ & $\begin{array}{c}\text { Number } \\
\text { of } \\
\text { Responde } \\
\text { nts }\end{array}$ & $\begin{array}{c}\text { Cronbach's } \\
\text { Alpha }\end{array}$ & Remarks \\
\hline $\begin{array}{c}\text { Satisfaction } \\
\text { towards the } \\
\text { Work Life } \\
\text { Balance }\end{array}$ & 21 & 602 & .886 & $\begin{array}{c}\text { Very Good } \\
\text { Value } \\
\text { (Alpha } \\
\text { value } \\
\text { between } \\
\text { Practices }\end{array}$ \\
\hline
\end{tabular}

Interpretation: Reliability shows the consistency in the responses of the respondents, hence it is important parameter to measure the normality of the data, and the reliability of the results generated based on the data collected using the reliable questionnaire. Here, in current study, researcher has used Cronbach Alpha method to measure the reliability of the data. The value of alpha is found above 0.70 , it is considered as acceptable value, and questionnaire is considered as reliable to be used for the further data analysis. In current study, the reliability of the one section was calculated using Cronbach Alpha method that was developed to measure the satisfaction level of the female faculty towards the work life balance practices prevailing in public and private universities of Delhi/NCR region. The total number of statements in this section were 21 and the number of respondents in the study were 602 female faculty. The value of Alpha was found to be 0.886 , which is above 0.70 , and lies between 0.80 to 0.90 which is considered as very good value and this section of the questionnaire was found to be reliable. Any results based on the data collected using these statements will give true picture of the construct.

\section{DESCRIPTIVE ANALYSIS}

This section comprises the results of the descriptive analysis done using mean, standard deviation and the skewness for all the 21 statements framed to measure the satisfaction level of the female faculty towards the work life balance practices prevailing in public and private universities of Delhi/NCR region.

\begin{tabular}{|l|c|c|c|c|c|}
\hline \multicolumn{1}{|c|}{ Table 2: Descriptive Statistics } \\
\hline & $\mathrm{N}$ & Mean & Std. Deviation & \multicolumn{2}{c|}{ Skewness } \\
\cline { 2 - 6 } & Statistic & Statistic & Statistic & Statistic & Std. Error \\
\hline Crèche facility & 602 & 3.0017 & 1.08153 & -.090 & .100 \\
\hline Child care leaves & 602 & 3.0631 & 1.07428 & .011 & .100 \\
\hline Feeding room & 602 & 3.2807 & 1.25696 & -.092 & .100 \\
\hline Flexible working hours & 602 & 3.2375 & 1.03598 & -.064 & .100 \\
\hline $\begin{array}{l}\text { Pickup drop facility from home }- \\
\text { Convenience \& security }\end{array}$ & 602 & 3.4319 & 1.36738 & -.362 & .100 \\
\hline Sponsored family tours & 602 & 3.2292 & 1.07332 & -.175 & .100 \\
\hline
\end{tabular}


An Examination To Measure The Satisfaction Level Of Faculty Towards Work Life Balance Practices Of Private And Public Universities Of Delhi/Ncr Region

\begin{tabular}{|c|c|c|c|c|c|}
\hline $\begin{array}{l}\text { Granting unpaid leaves with job } \\
\text { security to meet family } \\
\text { emergencies }\end{array}$ & 602 & 3.0199 & 1.23170 & -.043 & .100 \\
\hline $\begin{array}{l}\text { Appreciations, recognitions and } \\
\text { awards- To reduce the stress level } \\
\text { and give energy to cope with } \\
\text { family issues. }\end{array}$ & 602 & 3.0664 & 1.11661 & -.110 & .100 \\
\hline Maternity leaves & 602 & 3.2027 & 1.05212 & -.206 & .100 \\
\hline $\begin{array}{l}\text { Emergency leaves to take care of } \\
\text { sick children or parent or any } \\
\text { family members }\end{array}$ & 602 & 3.2857 & 1.04862 & -.279 & .100 \\
\hline $\begin{array}{l}\text { HR policies relating to posting } \\
\text { wife in the location where husband } \\
\text { works }\end{array}$ & 602 & 3.2841 & 1.22537 & -.152 & .100 \\
\hline Medical and casual leaves & 602 & 3.4086 & 1.16770 & -.102 & .100 \\
\hline $\begin{array}{l}\text { Family hospitalization insurance } \\
\text { cover }\end{array}$ & 602 & 3.1977 & 1.20003 & -.107 & .100 \\
\hline Term insurance for employee & 602 & 3.4419 & 1.07958 & -.176 & .100 \\
\hline $\begin{array}{l}\text { Providing workout facilities in the } \\
\text { office campus }\end{array}$ & 602 & 3.4983 & .99290 & -.093 & .100 \\
\hline $\begin{array}{l}\text { Promotion of family friendly } \\
\text { culture at office }\end{array}$ & 602 & 3.2940 & 1.29183 & -.026 & .100 \\
\hline $\begin{array}{l}\text { Carrier break for specific purpose } \\
\text { such as for higher education }\end{array}$ & 602 & 2.3987 & .92867 & .142 & .100 \\
\hline $\begin{array}{l}\text { Cafeterias providing nutritious } \\
\text { breakfast, lunch and snacks at } \\
\text { subsidized prices }\end{array}$ & 602 & 2.8389 & .91881 & -.218 & .100 \\
\hline $\begin{array}{l}\text { Holiday camps for the children } \\
\text { during vacation while parents } \\
\text { work }\end{array}$ & 602 & 2.9801 & .97195 & -.320 & .100 \\
\hline $\begin{array}{l}\text { Providing counselling services to } \\
\text { employees on work life balance }\end{array}$ & 602 & 2.8405 & .87362 & -.241 & .100 \\
\hline $\begin{array}{l}\text { Establishing various clubs such as } \\
\text { yoga, singing etc. to help cope } \\
\text { with stress. }\end{array}$ & 602 & 2.7309 & .86184 & -.250 & .100 \\
\hline Valid N (listwise) & 602 & & & & \\
\hline
\end{tabular}

Interpretation: Data has been collected from 602 female faculties working in twelve public and private universities situated in Delhi/NCR region. The highest mean value was found to be 3.49 , for the statement 'Providing workout facilities in the office campus", followed by the statement 'Term insurance for employee' and 'Pick and drop facility from home- Convenience \& security' with mean value of 3.44 and 3.43 respectively. While the lowest mean value was found 2.39 and 2.73 for the statements 'Carrier break for specific purpose such as for higher education' and 'establishing various clubs such as yoga, singing etc. to help cope with stresses'. Hence, it can be said that female faculty were found to be highly satisfied towards the workout facilities at their university campus for the female faculties, term insurance for faculty and pick and drop facility provided by the university, while the female faculty were found to be least satisfied towards the yoga club, or hobby clubs for faculty in the university campus. Further, the value of standard deviation for all the 21 statements were found to be less than or close to one, which indicates that there is no such variation in the responses of female faculty towards the satisfaction towards the work life balance practices prevailing in their universities. The skewness was measured to check the normality of the data, the value of the skewness lies between -1 to 1 is considered as normal data, while the value lies out of these limits will termed as skewed data. In current study, the value of 
skewness lies between minus one to one, hence data is termed as normally distributed and results obtained using this data can be generalized on the population. The missing value stats shows that there is no missing value in the data, and data has been screened before doing final analysis. Overall, it can be said that the descriptive analysis conducted on the data showed that there is consistency in the responses of the female faculty, and it's normally distributed. Further, the mean value analysis showed that universities need to work upon the establishment of yoga clubs, hobby clubs for the female faculty and should provide the facility of career break to pursue higher education or any other purpose. The overall mean values for all the 21 statements were found to be above two which shows that the overall the satisfaction among female faculty towards the work life balance practices prevailing in the universities was average only, neither satisfied nor dissatisfied.

$H_{0:}$ There is no significant difference in the satisfaction level of Female Faculty towards the work life balance practices of the Public and Private universities of Delhi/NCR.

$H_{1:}$ There is significant difference in the satisfaction level of Female Faculty towards the work life balance practices of the Public and Private universities of Delhi/NCR.

Researcher has used independent sample t-test to measure the difference in the mean values of the variable 'Satisfaction towards work life balance practices' among two groups of female faculty, one who is working in public universities and another group of female faculties working in private universities. Both these groups are independent in nature, and opinions and perception of one group do not get affected by the opinions or perceptions of another group.

\begin{tabular}{|c|c|c|c|c|c|}
\hline \multicolumn{6}{|c|}{ Table 3: Satisfaction towards WLB } \\
\hline & $\begin{array}{l}\text { University } \\
\text { Type }\end{array}$ & $\mathrm{N}$ & Mean & $\begin{array}{c}\text { Std. } \\
\text { Deviatio } \\
\mathrm{n}\end{array}$ & $\begin{array}{c}\text { Std. } \\
\text { Error } \\
\text { Mean }\end{array}$ \\
\hline \multirow{2}{*}{$\begin{array}{l}\text { Satisfactio } \\
\mathrm{n} \text { towards } \\
\text { WLB }\end{array}$} & $\begin{array}{l}\text { Public } \\
\text { University }\end{array}$ & $\begin{array}{c}44 \\
3\end{array}$ & $\begin{array}{c}3.322 \\
8\end{array}$ & .57544 & $\begin{array}{c}.0273 \\
4\end{array}$ \\
\hline & $\begin{array}{l}\text { Private } \\
\text { University }\end{array}$ & $\begin{array}{c}15 \\
9\end{array}$ & $\begin{array}{c}2.594 \\
2\end{array}$ & .27985 & $\begin{array}{c}.0221 \\
9\end{array}$ \\
\hline
\end{tabular}

Interpretation: The mean value of the variable 'Satisfaction towards WLB' was found to be higher for the public university i.e. 3.32, while the mean value for the variable 'Satisfaction towards WLB' was found to be lowest for private universities. It shows that the female faculties working in the public universities are more satisfied towards the work life balance practices prevailing in their universities while, the female faculties working in private universities were found to be least satisfied towards the work life balance practices prevailing in their universities. Further, the satisfaction level towards the work life balance practices prevailing in the universities has been measured using five point scale, hence the mean value in case of public universities was found to be above three which shows that the satisfaction level of female faculties working in private universities was above average, while the satisfaction level of female faculties working in private universities was found to be average only based on the mean value, which is less than three. Hence, public universities are providing better facilities to its faculties to help them in balancing their personal and professional life.

\begin{tabular}{|c|c|c|c|c|c|c|c|c|c|c|}
\hline \multicolumn{11}{|c|}{ Table 4: Results of Independent Sample T- Test } \\
\hline & & \multicolumn{2}{|c|}{$\begin{array}{l}\text { Levene's Test } \\
\text { for Equality } \\
\text { of Variances }\end{array}$} & \multicolumn{7}{|c|}{ t-test for Equality of Means } \\
\hline & & $\mathrm{F}$ & Sig. & $\mathrm{t}$ & $\mathrm{df}$ & $\begin{array}{c}\text { Sig. } \\
\text { (2-tailed } \\
\text { ) }\end{array}$ & \begin{tabular}{|c|} 
Mean \\
Difference
\end{tabular} & \begin{tabular}{|l} 
Std. Error \\
Difference
\end{tabular} & \multicolumn{2}{|c|}{\begin{tabular}{|c|}
$95 \%$ \\
Confidence \\
Interval of the \\
Difference
\end{tabular}} \\
\hline $\begin{array}{l}\text { Satisfaction } \\
\text { towards } \\
\text { WLB }\end{array}$ & $\begin{array}{c}\text { Equal } \\
\text { variances } \\
\text { assumed }\end{array}$ & $\begin{array}{c}90.29 \\
1\end{array}$ & .000 & 15.323 & 600 & .000 & .72863 & .04755 & $\begin{array}{c}.6352 \\
4\end{array}$ & $\begin{array}{c}.8220 \\
1\end{array}$ \\
\hline
\end{tabular}




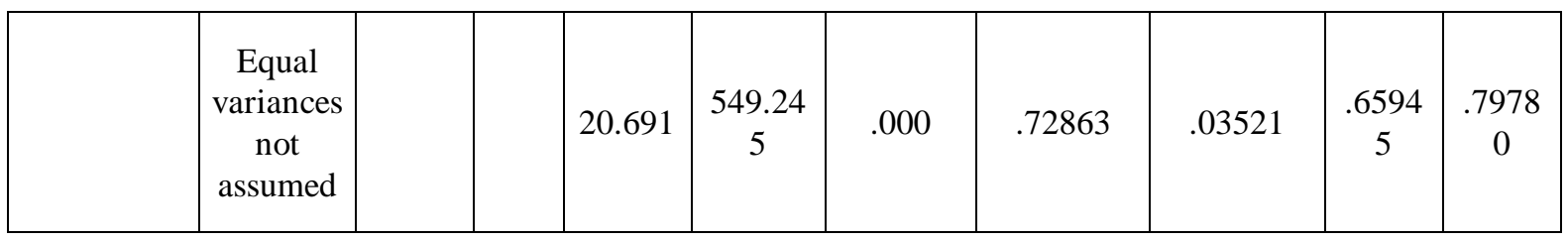

Interpretation: The results of levene's test and t-test were used to test the hypothesis in the current study. Levene's test value was found to be 90.291 , at a p-value of 0.000 , which indicates that there is a significant difference in the variance of the two groups of respondents' i.e. female faculties from public and private universities. As the variance for public and private universities for the variable 'Satisfaction towards WLB' was found to be significantly different, hence the value of t-test was taken when the unequal variance was assumed between two groups. The value of t-test corresponding to the unequal variance was found to be 20.691 , at a p-value of 0.000 , which indicates that there is a significant difference in the mean values of the variable 'Satisfaction towards WLB'. Hence, the null hypothesis got rejected and alternate hypothesis got accepted in the study, which states that there is a significant difference in the satisfaction level of Female Faculty towards the work life balance practices of the Public and Private universities of Delhi/NCR. Overall, it can be said that the private universities are not providing the various facilities to female faculties that can help in balancing the work and professional life. While public universities are better in this area and providing full facilities to help the female faculties in balancing their work and personal life. It also helps them to cope up the stress and perform better in the teaching area, while keeping their family happy by fulfilling all the responsibilities and giving proper time to the family also.

\section{CONCLUSION}

Overall, it can be said that the mean value of public university was found to be higher than private university for all the statements used to measure the satisfaction of female faculties towards the work life balance practices prevailing in the universities. This shows that the public universities are focusing higher than private universities for balancing the work and life of their female faculties. Balance in work and life is important for the better performance at the job and for a healthy social life of the female faculties. Private universities generally overburden the faculties, and provide less resources to complete their job. Female faculty usually do not avail the major facilities required to balance their personal and professional life. In teaching profession, usually the work from option is not prevalent, but other than this other facilities can be provided to the female faculties such as; paid maternity leaves, feeding rooms, crèche facility, child care leaves and other facilities where female faculties can enjoy their motherhood, their married life and can keep their family members happy and healthy.

\section{REFERENCES}

1. Alison, A. Rife and Rosaile, J. Hall (2015), "Work-Life Balance", SIOP White Paper Series White Paper Series, 2015, pp. 1-10.

2. Deline and Raya (2013), "A Study on Work Life Balance in Working Women", International Journal of Commerce, Business and Management, Vol. 2, Issue 5, October 2013, pp. 209-221.
3. International Labour Office (2011), "Work life Balance", Policy Development Section: Employment and Social Protection Segment, 312th Session, Geneva, November 2011, pp. 1-21.

4. Lyle, C. A. (2012), "Examination of the Employee Work-Life Balance with in Healthy Organizational Cultures", Thesis submitted with Gonzaga University, December 2012, pp. 1-56.

5. Mari, S. and O.M. HajaMohideen (2015),"A Study of Work-life Balance among the College Teachers in Pudukkottai and Thanjavur Districts", International Journal of Innovative Science, Engineering \& Technology, Vol. 2, Issue 7, July 2015, pp. 127-133.

6. Madipelli, S, Sarma, V. S. and Chinnappaiah, Y. (2013), "Factors Causing Work-Life Imbalance", The Indian Journal of Industrial Relations, Vo. 48, No. 4, 2013, pp. 621-633.

7. M. Monika (2015), "A Study on Work Life Balance at State Bank of Mysore", International Journal of in Multidisciplinary and Academic Research, Vol. 4, No. 3, June 2015, pp. 1-15.

8. Maya, Sahana and Bagali, M.M. (2014), "An Empirical Investigation on Work Life Balance among Working Mothers: Emerging HRM Interventions", International Journal of Business and Administration Research Review, Vol. 1, Issue 5, April-June 2015, pp. 166-178.

9. Paryani, Sneha (2014), "Study of Work-Life Balance of Faculties of engineering and Management Institutes with Special Reference to Mumbai and Pune Regions", Thesis submitted to D. Y. Patil University, Navi Mumbai, 2014, pp. 1-191.

10. Pookaiyaudom, G. (2015), “Assessing Different Perceptions towards the Importance of a Work-Life Balance: A Comparable Study between Thai and International Programme Students", Procedia-Social and Behavioral Sciences, Vol. 174, February 2015, pp. 267-274.

11. Saleh, H. B. (2015),"Work-Life Balance (WLB) Relationship with Employees Satisfaction: An Evidence from Malaysia Higher Education Institution", International Journal of Science Commerce and Humanities, Vol. 3, NO. 2, March 2015, pp. 50-55.

12. Shiels, R. S. (2014), "Changes in Work-Life Balance over Time: Implications for Job and Family Satisfaction", Thesis submitted with the school of applied psychology, Griffith University, May 2014, pp. 1-273.

13. Stella, Ojolbiyinka, SalauOdunayo Paul and Falola Hezekiah Olubusayo (2014), "Work-life Balance Practices in Nigeria: A Comparison of Three Sectors, Journal of Competitiveness, Vol. 6, Issue 2, 2014, pp. 3-14.

14. Skinner, Natalie and Janine Chapman (2013), "Work Life Balance and Family Friendly Policies", Evidence Base, Issue 4, 2013, pp. 1-25.

15. Sugana, G. and Franco, C. E. (2017), “A Study on Work Life Balance of Nursing Staff Working in Private Hospitals in Palayamkottai", International Journal of Research Granthaalayah, Vol. 5, Issue 8, SE, August 2017, pp. 72-75.

16. Rani, S., Kamalabhan et al., (2011), "Work/Life Balance Reflection on Employee Satisfaction", Serbian Journal of Management, Vol. 6, Issue 1, 2011, pp. 85-96.

17. Reddy, N. K. and Vranda, M. N. (2011), "work-life Balance among Married Women Employees", Indian Journal of Training and Development, Vol. 4, No. 2, 2011, pp. 1-11. 